\title{
Comparative Analysis of PI controller, Fuzzy controller and Interval Type-2 Fuzzy based Performance of Dynamic Voltage Restorer for Compensation of Voltage Sag and Swell
}

\author{
Bharti Thakur \\ Department of EEE \\ G.D.GOENKA \\ University \\ Gurgaon, India \\ thakur.bharti21@gmail.com
}

\author{
Dr. Archana Rani \\ Department of EEE \\ G.D.GOENKA \\ University \\ Gurgaon, India \\ archana.rani@gdgu.org
}

\begin{abstract}
In today's scenario, the power quality issues like voltage sag and swell are major concern in power system. At the distribution side to overcome this issue a custom power device DVR(Dynamic Voltage Restorer) is proven to be more effective solution which is lower in cost, smaller in size and offers faster dynamic response for the protection of sensitive load. DVR is a series compensating device which operates as voltage booster. The application of DVR entitlements to be a flawless compensating device for the compensation of voltage sag and swell. This paper presents the modelling and simulation using various controller topologies like PI controller based on synchronous reference frame algorithm, fuzzy controller and interval type 2 fuzzy controller. The results are then verified using Matlab-Simulink environment.
\end{abstract}

Keywords - Dynamic Voltage Restorer (DVR), Power Quality, SRF Algorithm, Fuzzy logic controller, Type 2 fuzzy controller (T2-Fuzzy), Voltage sag and swell.

\section{INTRODUCTION}

The Power quality problems like transients, voltage sag, voltage swell and others mainly affects the performance of system at the distribution side. These power quality issues mainly arises due to extensive use of sensitive critical loads. Amongst all the power quality issues[1], the variations in magnitude of voltage results in voltage sag and swell. Due to the continuous persistence of these problems in power system at the distribution side, various severe effects like complete shutdown of power plant, failure of equipment and unbalancing in the current takes place that shows the adverse impact on the distribution system. Voltage sag also known as voltage dip is defined as reduction in RMS voltage for short duration of time. Voltage sag can be caused by a sudden load change, transformer energizing, overloading, sudden start of motors ,short circuiting and some accidents like lightning in power lines. Voltage sag occurs when there is decrease in rms voltage in between 10 to $90 \%$ of nominal voltage for 0.5 cycle to 1 minute. Voltage swell is defined as an increase in rms voltage/current in between $1.1 \mathrm{pu}$ and $1.8 \mathrm{pu}$ for durations of 0.5 to 1 minute [2]. Voltage swell can be caused by deenergizing of heavy loads leading to hardware failure of device ,overheating and which could result to shutdown. To overcome this problem a custom power device, namely dynamic voltage restorer (DVR)[3] is used. A DVR is a power electronic device which is connected in series with the supply and the load to inject the required magnitude of voltage for compensation of voltage sag and swell. DVR mainly inject the difference between the rated voltage in comparison with the voltage variation[4]. It compensates both voltage sag and swell and also improves the regulation. The main role of DVR is detection and compensation of voltage sag and swell in the voltage at the source side[5] of power supply for the protection of load at distribution side from these power quality issues. This paper is systematized in following 7 sections i.e section1 has Introduction, section 2 discusses Operation of Dynamic Voltage Restorer (DVR), section 3,4,5 discusses Control strategy of DVR, section 6 shows Simulation diagram and results, and section 7 concludes the paper.

\section{OPERATION OF DVR}

Amongst all the power quality issues voltage sag/ swell are considered to have an severe impact on load at distribution side. To minimize the impact of voltage sag and swell or to protect various components of power system, the concept of custom power device were introduced[6]. Amongst all of them DVR is proven to be more efficient and cost effective. DVR provides high efficiency with more reliable operation.

For proper regulation of the voltage across load, the main role of DVR is injection of extra voltage to transmission system. The setting of dynamic voltage restorer is mostly situated at the distribution side i.e. in between distribution feeder and the load. DVR is a series compensating device which is connected in series between supply and the load at the point of common coupling at the distribution side[7]. It employs voltage boost technology using solid state switches of 3-phase voltage source converter. DVR uses this technology to get the desired output, by rebuilding of load side voltage. Besides the compensation of voltage sag and swell DVR helps in suppression of harmonics in phase voltages, falling of voltage spikes and also in restraining the fault current[8].

The figure. 1 shows the elementary structure of the dynamic voltage restorer( DVR). It consist of following parts[9].

1. Injection transformer or Boosting Transformesr

2.control circuit

3.filter circuit 
4.Voltage Source Converter

5.Energy storage devices like Capacitor and Battery which injects power.

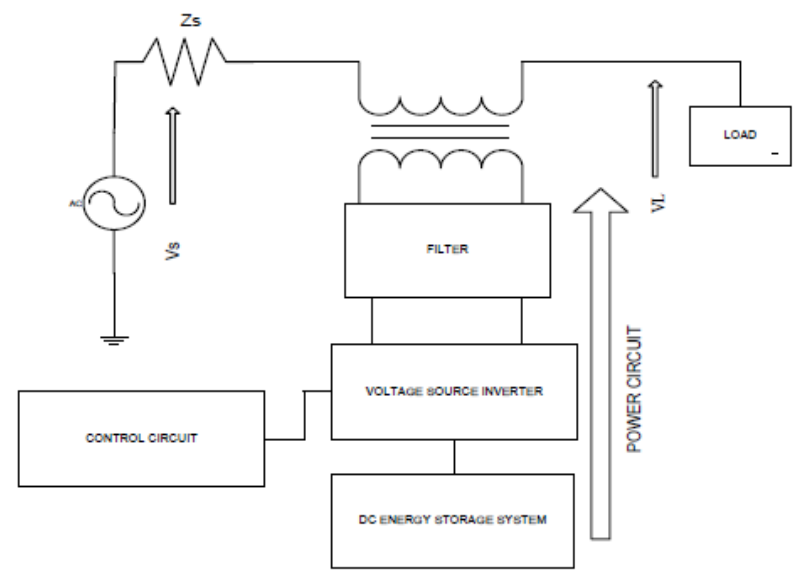

Fig. 1. Elementary construction of DVR[10].

Dynamic Voltage Restorer is deliberately consider to be the highly efficient and satisfactory resolution for the compensation of power quality issues like voltage sag and swell at the distribution side. At the point of common coupling during the fault conditions it helps in build up of load voltage profile[11]. It permits the exchange of both active and reactive power at the distribution side[11]. After the detection of the sag for building up of load voltage profile its operation swings from stand by mode to the active mode. For the boosting of 3-phase voltage, restoration of each phase voltage in magnitude and phase is done to the assigned pre-sag value of inverter switches in voltage source converter[12]. In Figure 2 it is clearly represented that the DVR supplies both reactive power $\left(Q_{\mathrm{DVR}}\right)$ or the real/active power $\left(\mathrm{P}_{\mathrm{DVR}}\right)[13]$, where $\mathrm{P}_{\mathrm{S}}$ and $\mathrm{Q}_{\mathrm{s}}$ signifies the active and reactive power of the supply mains and $P_{L} \& Q_{L}$ represents the active and reactive power of the load associated.

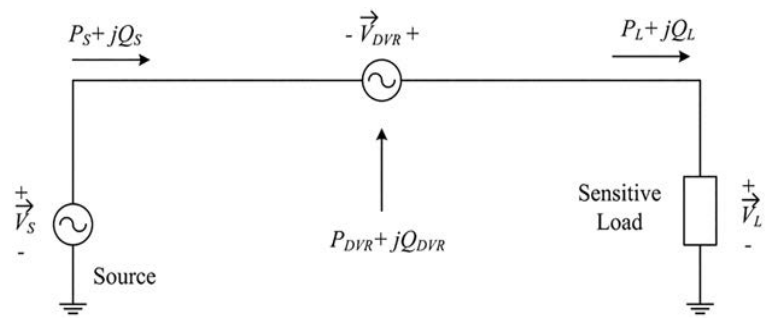

Fig. 2. Schematic diagram of DVR [14].

The main configuration of DVR comprises of power circuit and control circuit [15]. In figure 3 the equivalent circuit is shown and the corresponding equations are given below.

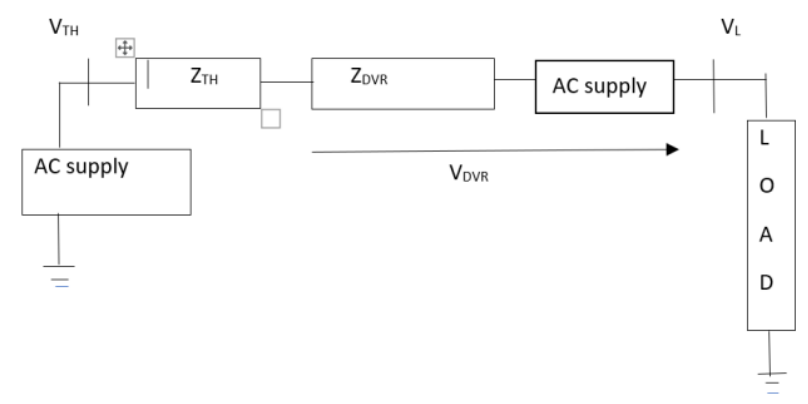

Fig. 3. Equivalent structure of DVR.

$$
V_{D V R}=V_{T H}+I_{L} Z_{T H}+V_{L}
$$

Where the magnitude of required load voltage is represented by $\mathrm{V}_{\mathrm{L}}$, load impedance by $\mathrm{Z}_{\mathrm{TH}}$ and load current[16] is represented by $\mathrm{I}_{\mathrm{L}}$, and is shown in equation 2 .

$$
I_{L}=\frac{P_{L}+j Q_{L}}{V_{L}}
$$

In equation $3, \alpha$ is angle of DVR voltage $\left(\mathrm{V}_{\mathrm{DVR}}\right)$ and $\beta$ is angle of $\mathrm{V}_{\mathrm{TH}}$ and in equation 4 power angle of loadbis represented by $\theta$.

$V_{D V R}<\alpha=V_{L}<0+Z_{T H} I_{L}<(\beta-\theta)+V_{T H}<\delta$

$$
\theta=\tan ^{-1} \frac{Q_{L}}{P_{L}}
$$

The injection of complex power [16] by DVR is given in equation 5 and is represented by $S_{\text {DVR. }}$

$$
S_{D V R}=V_{D V R} I_{L}^{*}
$$

\section{SYNCHRONOUS REFERENCE FRAME THEORY}

The control block diagram of the capacitor supported DVR employing synchronous reference frame (SRF) theory is shown in figure 4. At the point of common coupling (PCC) employing the abc to dq0 conversion, voltages are converted to the rotating reference frame[17]. The Low pass filters (LPF) are used to eliminate the harmonics and oscillations in voltages. The Synchronous Reference Frame (SRF) algorithmic employs Park's transformation in which abc frame load voltages are converted into the rotating reference (dq0) by adopting abc-dq0 conversion as shown in equation $1[18]$.

$\left[\begin{array}{l}v_{l d} \\ v_{l q} \\ v_{l o}\end{array}\right]=\frac{2}{3}\left[\begin{array}{ccc}\cos \theta & -\sin \theta & \frac{1}{2} \\ \cos \left(\theta-\frac{2 \pi}{3}\right) & -\sin (\theta-2 \pi / 3) & \frac{1}{2} \\ \cos \left(\theta+\frac{2 \pi}{3}\right) & \sin (\theta+2 \pi / 3) & \frac{1}{2}\end{array}\right]\left[\begin{array}{l}v_{l a} \\ v_{l b} \\ v_{l c}\end{array}\right]$

The conversion of the rotating reference frame load voltages $\left(\mathrm{v}_{\mathrm{ld}}, \mathrm{v}_{\mathrm{lq}}, \mathrm{v}_{\mathrm{l}}\right)$ into the abc frame load voltages is done by adopting $\mathrm{dq} 0$-abc conversion using reverse park's transformation as shown in shown in equation 2.

$\left[\begin{array}{l}v_{l a} \\ v_{l b} \\ v_{l c}\end{array}\right]=\frac{2}{3}\left[\begin{array}{ccc}\cos \theta & \sin \theta & 1 \\ \cos \left(\theta-\frac{2 \pi}{3}\right) & \sin (\theta-2 \pi / 3) & 1 \\ \cos \left(\theta+\frac{2 \pi}{3}\right) & \sin (\theta+2 \pi / 3) & 1\end{array}\right]\left[\begin{array}{l}v_{l d} \\ v_{l q} \\ v_{l o}\end{array}\right]$ 
For the mitigation of power quality issues like voltage sag, a capacitor-supported DVR connected system is employed which inject the voltage in-quadrature with the load current at fundamental value of frequency[19]. Filters like low pass filters have been used to eliminate the ripples and several oscillations in the source voltages. The various components of point of common coupling (PCC) voltages along d-axes and q-axes are shown in shown in equation 3 and 4 where $v_{\text {sddc }}$ and $v_{\text {sqdc }}$ are fundamental components respectively of $\mathrm{v}_{\mathrm{sd}}$ and $\mathrm{v}_{\mathrm{sq}}$ along $\mathrm{d}$ axis[20]. The harmonic and oscillatory components respectively of $\mathrm{v}_{\mathrm{sd}}$ and $\mathrm{v}_{\mathrm{sq}}$ along $\mathrm{q}$-axis are represented as $\mathrm{v}_{\mathrm{sdac}}$ and $\mathrm{v}_{\text {sqac. }}$.

$v_{s d}=v_{s d d c}+v_{s d a c}$

$v_{s q}=v_{s q d c}+v_{s q a c}$

The mitigation techniques decide the compensating strategy for voltage compensation for the better power quality. It also specifies that the load terminal voltage should be of rated extent without any distortion. For controlling the DC-link voltage to its reference value i.e $\mathrm{v}_{\mathrm{dc}}=200 \mathrm{~V}$ the PI controller is employed in the DC link control loop. Due to switching of VSC [21]the output of PI controller consider as active component of voltage resulting in voltage loss $\mathrm{v}_{\text {loss }}$ as shown in equation 5 .

$v_{l o s s(n)}=v_{l o s s(n-1)}+k_{i 1} e_{d c(n)}+k_{p 1}\left(e_{d c(n)}-e_{d c(n-1)}\right)$

The difference between the reference DC link voltage $\mathrm{v}_{\mathrm{dc}}$ *and the DC voltage sensed at $\mathrm{n}^{\text {th }}$ sample[22] is represented by $\mathrm{e}_{\mathrm{dc}(\mathrm{n})}$ and $\mathrm{k}_{\mathrm{p} 1}$ and $\mathrm{k}_{\mathrm{i} 1}$ are the proportional and integral gains of the PI controller in the loop. Along the d-axis the reference load voltage is shown in equation 6 .

$v_{l d} *=v_{s d d c}-v_{l o s s}$

During the voltage sag condition the amplitude of the load terminal voltage $\left(\mathrm{v}_{\mathrm{lp}}\right)$ reduces and thus PI controller is used in the AC-link control loop[23] for controlling the AC-link voltage to its reference value i.e $\mathrm{v}_{\mathrm{lp}}=326$ volts. For controlling the AC-link voltage the reactive component $\mathrm{v}_{\mathrm{qr}}$ of PI controller [24]is considered. The amplitude of the AC-link voltage i.e $v_{l p}$ at the output of point of coupling is derived from the instantaneous values of the AC load voltages ( $\mathrm{v}_{\mathrm{la}}, \mathrm{v}_{\mathrm{lb}}, \mathrm{v}_{\mathrm{lc}}$ ) as shown in equation 7.

$v_{l p}=\sqrt{2 / 3}+\left(v_{l a}^{2}+v_{l b}^{2}+v_{l c}^{2}\right)^{1 / 2}$

The quadrature section of the load terminal voltage i.e AClink voltage [25][26] is regulated by PI controller as shown in equation 8 .

$v_{q r(n)}=v_{q r(n-1)}+k_{i 2} e_{l p(n)}+k_{p 2}\left(e_{l p(n)}-e_{l p(n-1)}\right)$

Along the q-axis the reference load voltage is shown in equation 9. The equation 10 shows the reverse park transformation in which the rotating reference frame load voltages are converted back into the reference load voltages, where the error between the sensed load voltage and the reference load voltages are utilized in PWM to produce gate pulses for the VSC of DVR[27] .

$v_{l q} *=v_{s q d c}+v_{q r}$ $\left[\begin{array}{l}v_{l a} * \\ v_{l b} * \\ v_{l c} *\end{array}\right]=\left[\begin{array}{ccc}\cos \theta & \sin \theta & 1 \\ \cos \left(\theta-\frac{2 \pi}{3}\right) & \sin (\theta-2 \pi / 3) & 1 \\ \cos \left(\theta+\frac{2 \pi}{3}\right) & \sin (\theta+2 \pi / 3) & 1\end{array}\right]\left[\begin{array}{l}v_{l d} * \\ v_{l q} * \\ v_{l o} *\end{array}\right]$

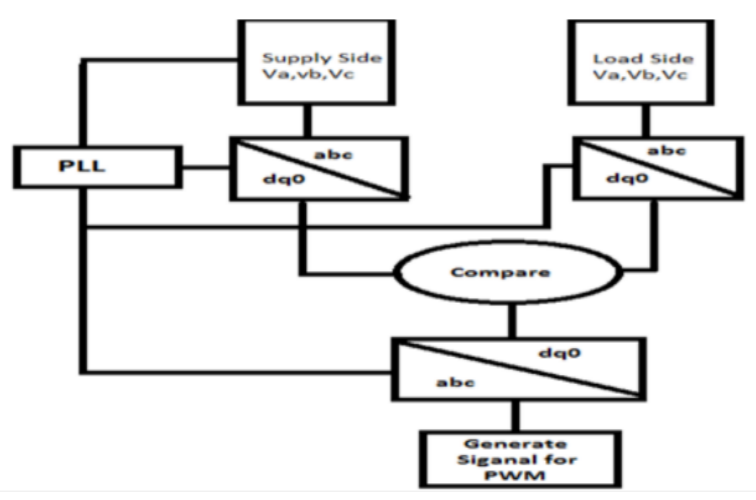

Fig.4. Control block diagram of SRF Baesd DVR[28].

The Performance depends on the tuning of the gains, $\mathrm{k}_{\mathrm{p} 2}$ and $\mathrm{k}_{\mathrm{i} 2}$ of the PI controllers.

\section{FUZZY LOGIC CONTROLLER}

In this paper, a conventional fuzzy logic controller based feedback controller is used for controlling the injection of the voltage in the proposed Dynamic Voltage Restorer (DVR). The conventional Fuzzy logic controller is favored over the conventional SRF based PI controller due to its simplicity and easier operation which provide strength in the variation of system parameters. The earlier used PI controller faces problem in controlling the injected voltage as it is more inclined to parameter variation of energy storage system used in DVR as the amount of energy stored varies with the voltage sag/swell events[28]. The energy storage system used in DVR are consisting of capacitors, which are charged directly from the power supply using rectifier. On the basis of energy stored in dc link capacitors, the output of inverter depends. To overcome the problems faced by PI controller based DVR and to improve the performance in both steady and transient state, a fuzzy logic controller is implemented in the system which let go the system from the precise and bulky mathematical calculations.

The basic block diagram of fuzzy logic controller is shown in figure 5 which comprises of knowledge base, fuzzification, inference mechanism and defuzzification.

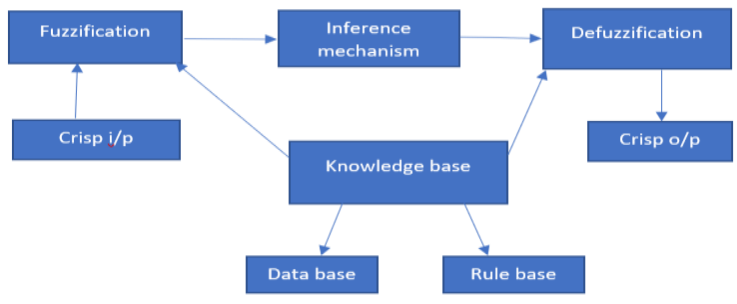

Fig.5. Basic block diagram of Fuzzy logic controller[29]. 
Fuzzification: In FLC system, there is a need to have that variable linked with input/output state which defines each set have control surface that could have been expressed in notations of fuzzy set using level of linguistic terms. The extent to which a variable belong to a particular level have been denoted through member value of each set of input and output variables[30]. Fuzzification is defined as the term where the set of input and output have been converted into linguistic value.

Inference: The behavior required by the control surface that relates variables at input and output side of the system has been governed with various set of rules. The explanation would be taken with the logistics rule such that if $\mathrm{z}$ is $\mathrm{A}$ then $\mathrm{x}$ is $\mathrm{B}$. When each rule has been read out with input variables that contain any degree of truth in its premise has been fired and which contributed to the forming by modifying approximately of the control surface in it. The constraints related to output of the fuzzy rule base system has been expressed when all rules were fired accordingly.

Defuzzification: When we convert the value of fuzzy parameter into the corresponding crisp value then it is known as Defuzzification.

Data Base: When membership function stores the value of database required by de-fuzzifier and fuzzifier. There is a compromise between the given memory and mips of the controller chip in digital form which have been given to the storage format.

Rulebase: Rule evaluator required the rule base in lingustistic level which was created by rule base system.

\section{TYPE 2 FUZZY LOGIC CONTROLLER}

The conventional Fuzzy Logic Controllers (FLCs) have been implemented to many devices with boundless success to unlimited applications. Though, for many real-life applications, there is requirement to deal with these large quantities of uncertainties. The conventional fuzzy logic controller ( FLC) that uses fuzzy sets of crisp input are not able to handle these uncertainties directly. Type-2 fuzzy logic controller that use type- 2 fuzzy sets can easily handle such uncertainties to produce a better performance. Hence, type-2 FLCs will have the potential to overcome the limitations of conventional FLC and produce a new generation of fuzzy controllers with improved performance for many applications which require handling high levels of uncertainty.

Hence in continuation to this to get improved quality of power, a strategy has been used to tune the gains of the PI controllers using Type 2 fuzzy logic controller [26].As if now the conventional or Type1 Fuzzy logic controller are proven to be very successful to different applications besides having large amount of un-certainties in real world applications[18][29]. The conventional Type 1 Fuzzy logic controller uses crisp fuzzy sets that are not capable to handle these uncertainties. A type-2 fuzzy set is characterised by a fuzzy membership function, i.e. the membership value (or membership grade) for each element of this set is a fuzzy set in $[0,1]$, unlike a conventional fuzzy set where the membership grade is a crisp number. Though to overcome the limitations of conventional Fuzzy logic controller, Type2 Fuzzy logic controllers are considered to be new generation with better performance for many applications requiring handling of high level of uncertainties [31]. With the use of type 2 fuzzy it is observed that the degree of freedom is high and 3D is used instead of 2D, enabling to control the un-certainties [32][33]. It improves the total harmonic distortion resulting in better power quality

\section{SIMULATION DIAGRAM AND RESULTS}

Here, sag/swell events are simulated in the $v_{\text {in }}(t)$ abc voltage. The output voltage $v_{\text {out }}(t) a b c$ is found to be constant due to injected voltage $\mathrm{v}(\mathrm{t})$ inj abc which is generated by different controllers. Figure 6 shows the THD analysis at the load side voltage before voltage sag/sell compensation i.e without implementation of DVR. Following test parameters have been considered as given below:

Between $\mathrm{t}=0.1 \mathrm{~s}$ and $\mathrm{t}=0.2 \mathrm{~s}$, a voltage $\mathrm{sag} / \mathrm{swell}$ is introduced at the source side voltage impacting the power quality of load side voltage. To suppress these harmonics various controllers are implemented. The effect of voltage sag (introduced at the source side) on terminal voltage of linear load is compensated using SRF based PI controller, conventional fuzzy Logic controller and a novel technique of type 2 fuzzy controller.

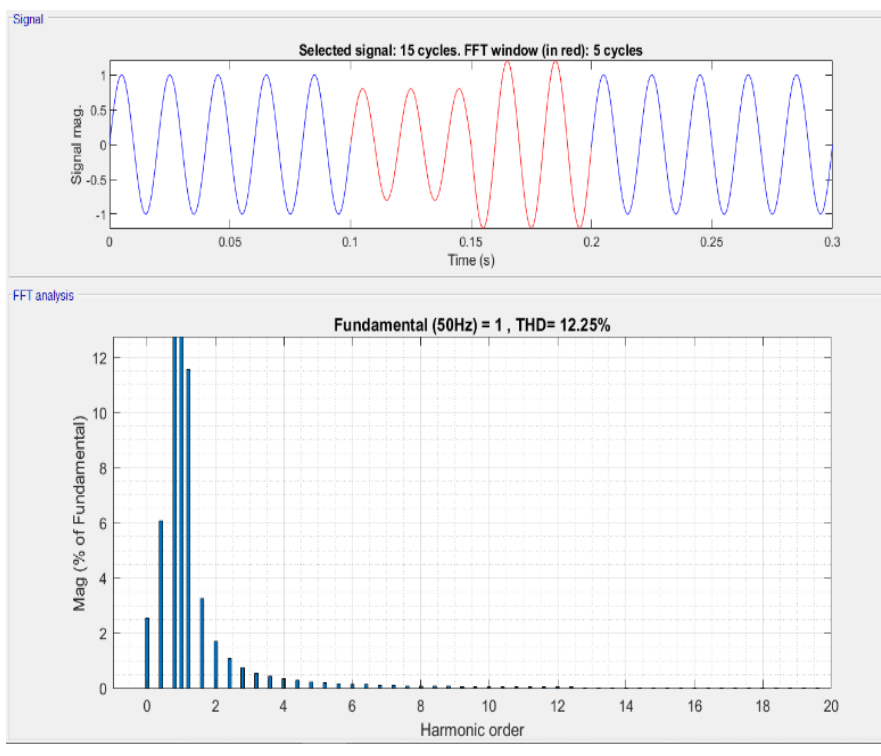

Fig.6 THD at the load side voltage before voltage sag/swell compensation i.e without DVR.

\section{A. Simulation and Result with SRF based PI controller}

To suppress the voltage sag/swell SRFA based PI controller is implemented. The effect of voltage sag (introduced at the source side) on terminal voltage of linear load is compensated using SRF based PI controller. When the source voltage experiences large sag of magnitude as high as $20 \%$ voltage sag at that time DVR plays the role of a series compensator. Figure 8 represent the plots of voltage at the point of common coupling (PCC)and load terminal voltage with SRF based controller 
under the influence of $20 \%$ voltage sag in the supply voltage. For the time duration of $0.1-0.2 \mathrm{~s}$, a sag is introduced in the supply voltage due to which the load terminal voltage $\mathrm{v}_{\text {labc }}$ suffers correspondingly with sag. Thus the linear sensitive load would face voltage power quality issues. It is observed that the sag of $20 \%$ for the duration of five cycles is found to be a serious condition. As a result the system would be unable to meet the desired requirement of output voltage at load side without DVR. Thus DVR is employed to inject the voltage to compensate the voltage sag. The basic simulink model of DVR is shown in figure 7 .

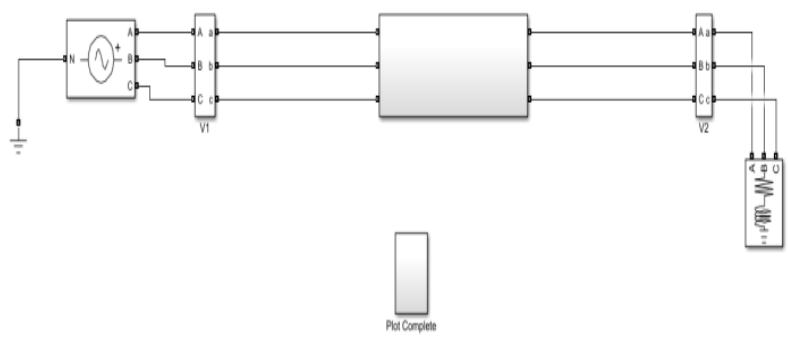

Fig.7 Simulink model of DVR.

The simulation time for sag occurring in the system is $0.1 \mathrm{~s}-0.2 \mathrm{~s}$ for five cycles. DVR effectively injects the desired magnitude of compensating voltage, $v_{\text {cab }}$ to regulate the voltage at load side in the system where $v_{\text {labc }}$ is load side voltage and $v_{d c}$ is $d c$ link voltage using SRF based PI controller as shown in figure 8. By proper tuning of $\mathrm{k}_{\mathrm{p}}$ and $\mathrm{k}_{\mathrm{i}}$ of SRF based PI controller, the desired compensating voltage $\mathrm{v}_{\text {cabc }}$ can be achieved as shown in figure9 where complete plot is represente.

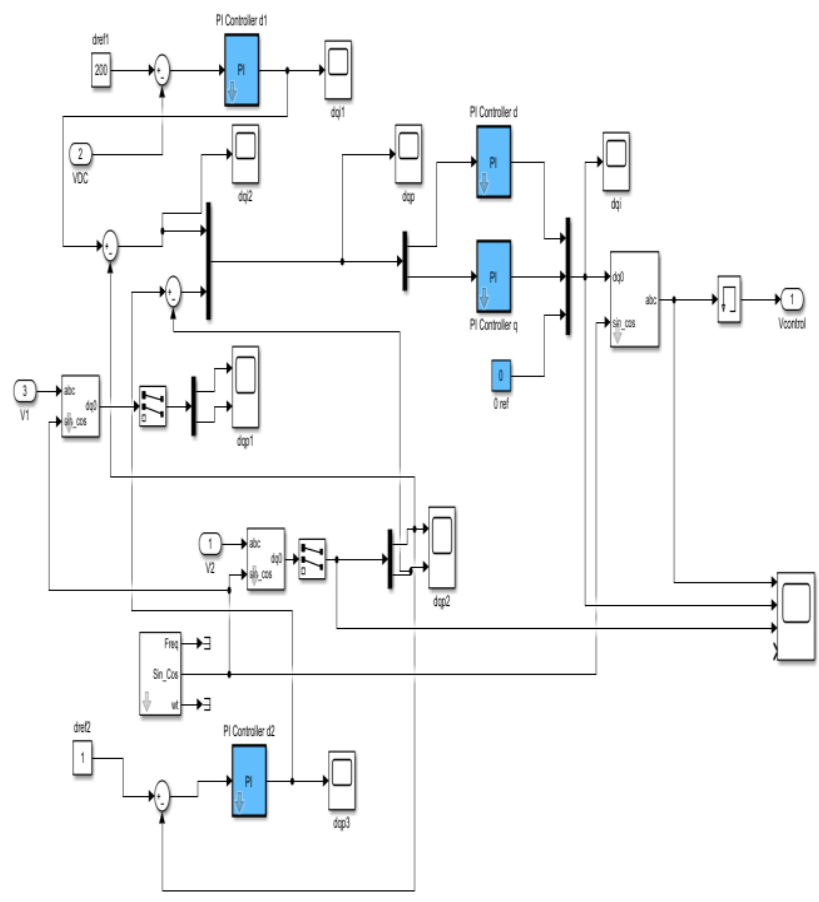

Fig.8 Simulink model of SRFA based PI Controller.

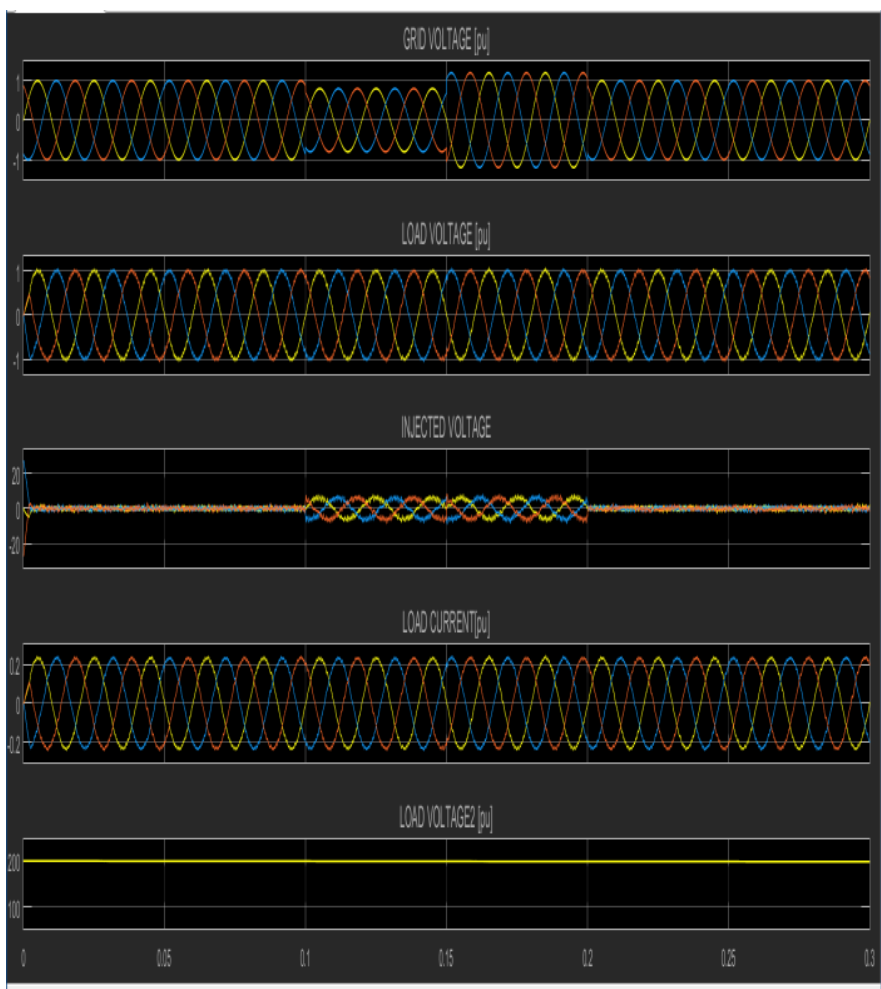

Fig.9 Plot for Grid voltage, Load voltage, Injected voltage ,Load current, dc voltage after sag compensation using SRFA based PI controller DVR.

The SRF based PI tuned DVR voltage controller gives better result as compared to when used without DVR with THD of $4.42 \%$ at the load side as shown in figure 10 . For severe voltage sag of $20 \%$ at source side, a THD of less than $5 \%$ is obtained with a maximum value of only $4.42 \%$ using this technique.

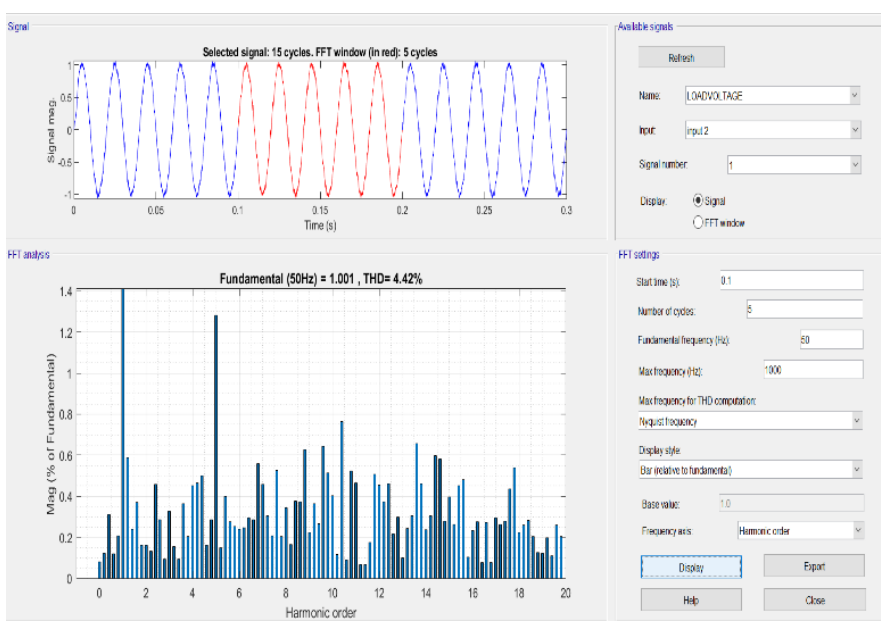

Fig.10 THD at the load side voltage after voltage sag compensation using SRFA based PI controller DVR.

B. Simulation and Result with conventional Fuzzy logic controller based DVR

The Simulink model of conventional Fuzzy logic controller is shown in figure 11 which is used in favor over the conventional SRF based PI controller due to its simplicity and easier operation which provide strength in the variation of system parameters. Fig 12 shows the THD improvement of $3.50 \%$ at 
the load side voltage after voltage sag compensation using conventional Fuzzy logic controller based DVR which is far better performance as compared to SRF based PI controller.

Conventional fuzzy logic Controller

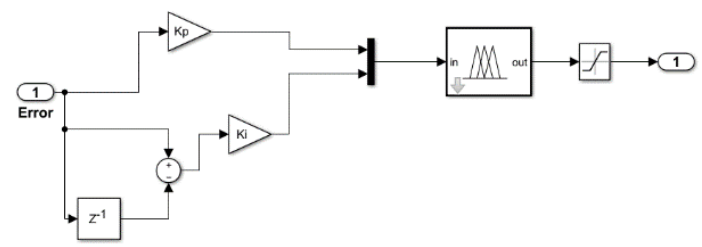

Fig.11.Simulink model of conventional Fuzzy logic Controller.

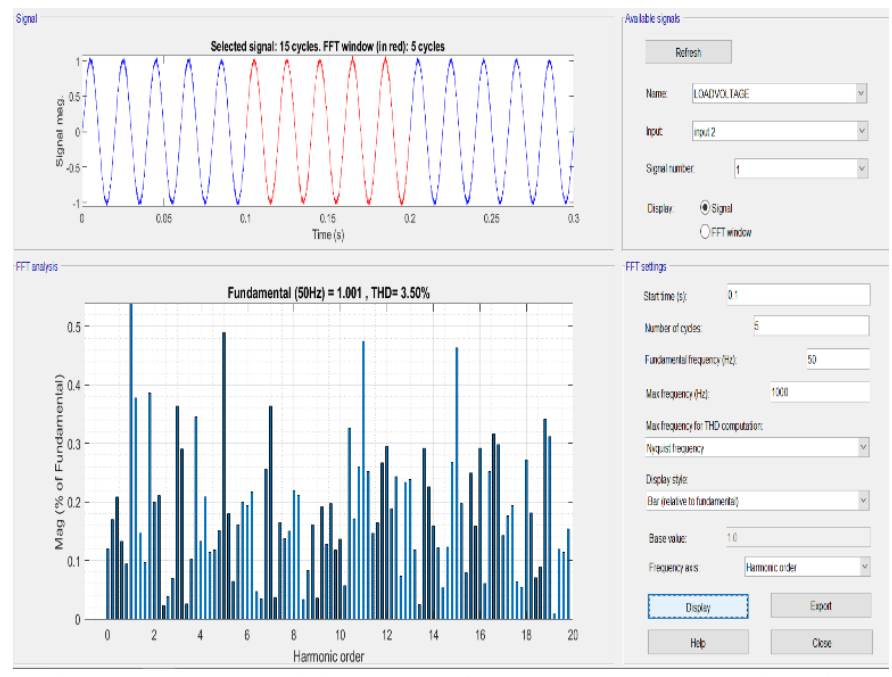

Fig 12.THD at the load side voltage after voltage sag compensation using conventional Fuzzy logic controller based DVR.

C. Simulation and Result with Type 2 Fuzzy controller based DVR

For optimal injection of compensating voltage at the load side, a robust novel technique using Type-2 Fuzzy controller is employed as shown in figure 13.From above figure, it is concluded that DVR has successfully maintained $\mathrm{v}_{\mathrm{dc}}$ to its

rated value proving its dynamic response with validation. The performance of designed controller in the DVR system is able to regulate the balanced sag condition. The introduced sag of $20 \%$ in each of the three phases of supply voltage. With the help of PI tuned DVR using Type2 Fuzzy Logic Controller technique the mitigation of voltage sag with better power quality is achieved along-with the regulation of the DC-link voltage close to $200 \mathrm{~V}$ as shown in figure 14 .

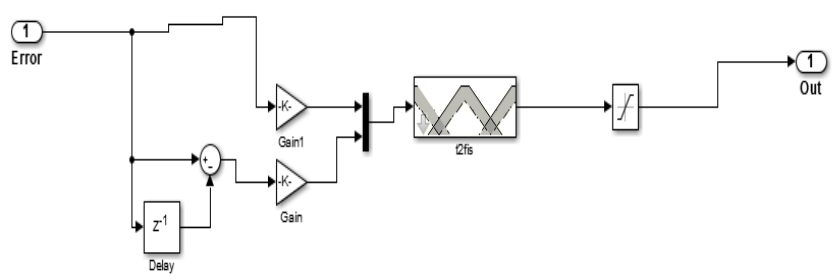

Fig.13.Simulink model of Type 2 Fuzzy Controller.

It is observed that the by using the Type 2 fuzzy controller the degree of freedom is high and 3D is used instead of 2D, enabling to control the un-certainties. It improves the total harmonic distortion resulting in better power quality after the compensation of voltage sag/swell.

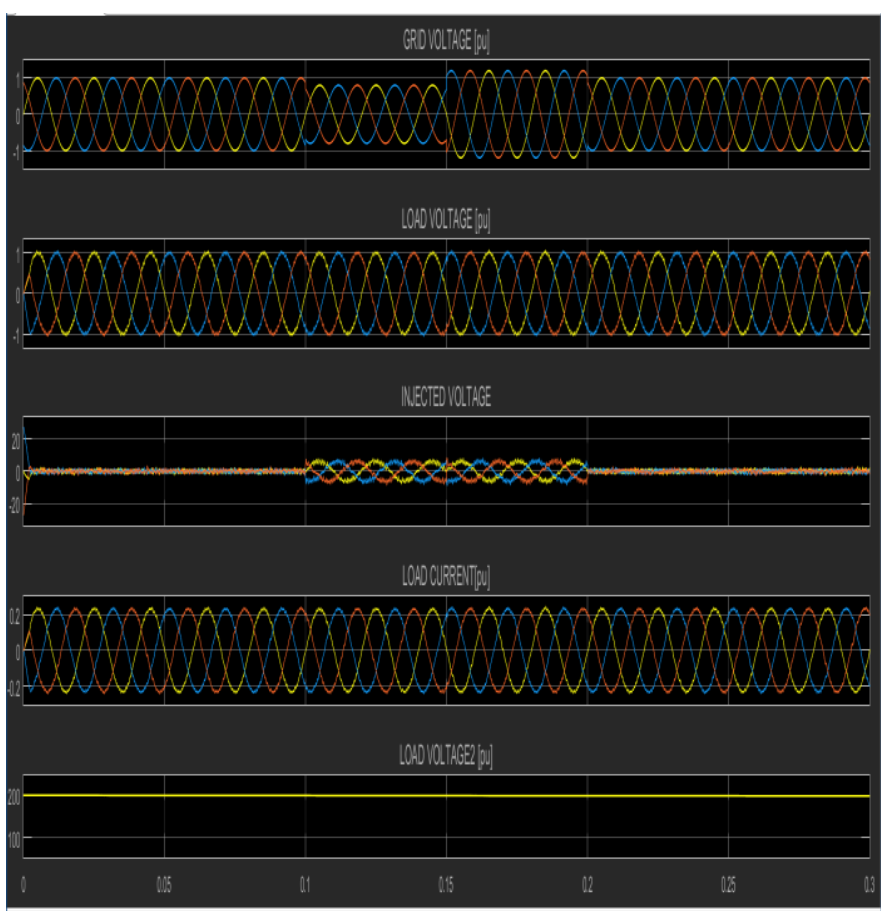

Fig.14.Plot for Grid voltage, Load voltage, Injected voltage ,Load current, dc voltage after sag compensation using Type 2 fuzzy controller.

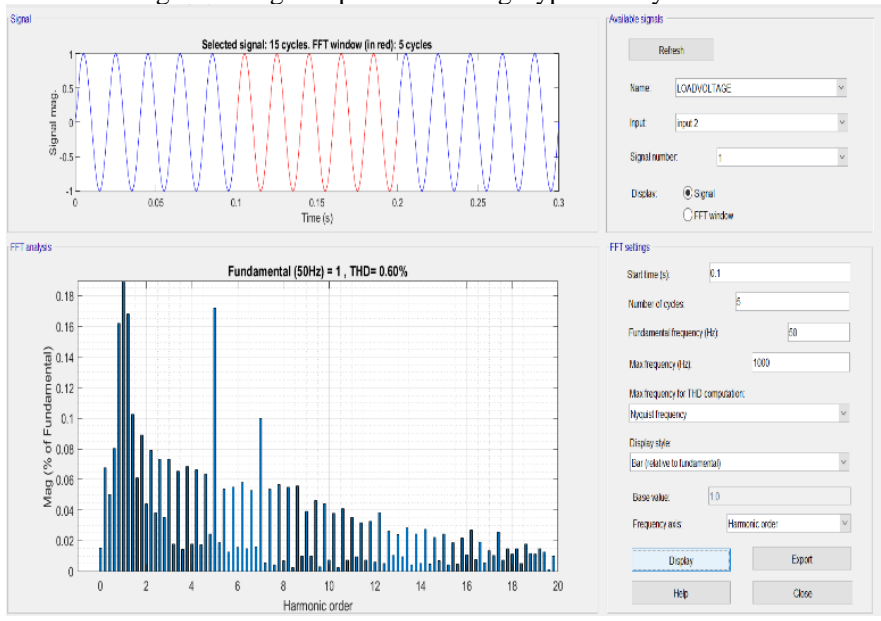

Fig.15.THD at the load side voltage after voltage sag compensation using Type 2 Fuzzy based DVR . 
The type-2 fuzzy-tuned PI DVR voltage controller provides better result as compared to SRF tuned PI DVR with THD of $0.60 \%$ at the load side as shown in figure 15 . For severe voltage sag of $20 \%$ at source side, a THD of less than $5 \%$ is obtained with a maximum value of only $0.60 \%$ using this novel technique. The comparative analysis of various controller implemented with DVR is shown in figure 16 which clearly illustrate that the type-2 fuzzy logic controller has proven to be better controller as compared to other two.

\begin{tabular}{|c|c|c|c|}
\hline Factor & With PI DVR & $\begin{array}{l}\text { With Fuzzy logic } \\
\text { controller DVR }\end{array}$ & $\begin{array}{l}\text { With TYPE-2 Fuzzy } \\
\text { Logic controller }\end{array}$ \\
\hline $\begin{array}{l}\text { Sag 20\% } 20 \text { (sec) }=0.1 . \\
0.15\end{array}$ & Compensated & Compensated & Compensated \\
\hline $\begin{array}{l}\text { swell } 20 \% \mathrm{t}(\mathrm{sec})=0.15- \\
0.2\end{array}$ & Compensated & Compensated & Compensated \\
\hline Multi mode oscillations & observed & Not observed & Not observed \\
\hline Source side THD & $12,25 \%$ & $12.25 \%$ & $12.25 \%$ \\
\hline Load side THD & $4,42 \%$ & $3.50 \%$ & $0.60 \%$ \\
\hline
\end{tabular}

Fig.16. Comparative analysis of various controller implemented with DVR.

\section{CONCLUSION}

This paper mainly concern with power quality issues like voltage sag and swell affecting the loads at the distribution side. For the compensation of these problems a series compensating device, DVR is presented. Simulation results obtained proves that DVR is efficient compensating device for both sag and swell. For various controller a comparative analysis is shown which proves that interval type 2 fuzzy controller gives better performance than the conventional fuzzy logic controller and SRF based PI controller. This proposed interval type 2 fuzzy controller implementation has no gains to adjust and this controller resolve the problem of tuning of gains included in conventional fuzzy logic controller.

\section{References}

[1] P. C. Patil, "Improvement of Power Quality using DVR," Int. J. Res. Appl. Sci. Eng. Technol., vol. 6, no. 1, pp. 304-309, 2018, doi: 10.22214/ijraset.2018.1046

[2] C. H. Rovai and A. Doorwar, "An overview of various control techniques of DVR," 2014, doi: 10.1109/ICCPCT.2014.7054844.

[3] S. Sharma, N. Goel, and V. Swarnkar, "Voltage Sag Mitigation by DVR," vol. 3, no. 12, pp. 138-141, 2013.

[4] A. K. Sadigh and K. M. Smedley, "Review of voltage compensation methods in dynamic voltage restorer (DVR)," IEEE Power Energy Soc. Gen. Meet., no. August, 2012, doi: 10.1109/PESGM.2012.6345153.

[5] V. Tech, "MODELING AND SIMULATION OF DVR AT DISTRIBUTION LOAD SIDE FOR,” vol. 13, no. 1, pp. 525-529, 2015.

[6] M. Zadehbagheri, R. Ildarabadi, and M. B. Nejad, "Review of dynamic voltage restorer application for compensation of voltage harmonics in power systems," Indonesian Journal of Electrical Engineering and Computer Science. 2017, doi: 10.11591/ijeecs.v5.i1.pp58-71.

[7] A. P. Torres, P. Roncero-Sánchez, X. Del Toro García, and V. F. Batlle, "Generalized Proportional-Integral control for voltage-sag compensation in Dynamic Voltage Restorers," 2011 7th Int. Conf. Compat. Power Electron. CPE 2011 - Conf. Proc., pp. 92-97, 2011, doi: 10.1109/CPE.2011.5942213.

[8] S. P. Mishra, B. Biswal, J. P. Roselyn, and D. Devaraj, "Simulation and analysis of DVR for mitigating voltage sags and swells," Procedia Eng., vol. 64, pp. 341-350, 2013, doi:

10.1016/j.proeng.2013.09.106

[9] P. C. Patil, "Improvement of Power Quality using DVR," Int. J. Res. Appl. Sci. Eng. Technol., vol. 6, no. 1, pp. 304-309, 2018, doi: 10.22214/ijraset.2018.1046.

[10] C. H. Rovai and A. Doorwar, "An overview of various control techniques of DVR," 2014, doi: 10.1109/ICCPCT.2014.7054844. S. Sharma, N. Goel, and V. Swarnkar, "Voltage Sag Mitigation by DVR," vol. 3, no. 12, pp. 138-141, 2013.

[12] A. K. Sadigh and K. M. Smedley, "Review of voltage compensation methods in dynamic voltage restorer (DVR)," IEEE Power Energy Soc. Gen. Meet., no. August, 2012, doi:

10.1109/PESGM.2012.6345153.

V. Tech, "MODELING AND SIMULATION OF DVR AT DISTRIBUTION LOAD SIDE FOR," vol. 13, no. 1, pp. 525-529, 2015.

[14] S. P. Mishra, B. Biswal, J. P. Roselyn, and D. Devaraj, "Simulation and analysis of DVR for mitigating voltage sags and swells," Procedia Eng., vol. 64, pp. 341-350, 2013, doi: 10.1016/j.proeng.2013.09.106.

[15] T. K. Sahu, "Neural Network Control for Power Quality Enhancement Using Dynamic Voltage Restorer,” pp. 1448-1452, 2017.

[16] S.H Hossein,A.H Etimadi,"Adaptive Neuro-Fuzzy Inference System Based Automatic Generation Control," Electr. Power Syst. Res., vol.78, no. 7, pp. 1230-1239, 2008

[17] P. Suresh, B. Baskaran, and G. Ramya, "Fuzzy Logic Controller Based IDVR in IEEE 30 Bus System for Voltage Sag Compensation," Indian J. Sci. Technol., vol. 10, no. 29, pp. 1-7, 2017.

[18] B. V. Kumar, R. S. Bhatia, and P. Nijhawan, "Power Quality Enhancement Using SVPWM Z-Source Inverter Based DVR," in India International Conference on Power Electronics, IICPE, 2017.

[19] D. Somayajula and M. L. Crow, "An Integrated Dynamic Voltage Restorer-Ultracapacitor Design for Improving Power Quality of the Distribution Grid," IEEE Trans. Sustain. Energy, 2015.

[20] N. Kassarwani, J. Ohri, and A. Singh, "Design and Performance of Dynamic Voltage Restorer using Genetic Algorithm," Int. J. Electron., vol. 105, no. 1, pp. 88-103, 2018.

[21] J. G. Nielsen and F. Blaabjerg, "A Detailed Comparison of System Topologies for Dynamic Voltage Restorers,” IEEE Trans. Ind. Appl., 2005.

[22] Elserougi, A., Massoud, A. M., Abdel-Khalik, A. S., Ahmed, S., and Hossam-Eldin, A. A. (2014)." An Interline Dynamic Voltage Restoring and Displacement Factor Controlling Device (IVDFC) IEEE Transactions on Power Electronics, 29(6), 2737-2749.

[23] Chan, K, and Kara A, "Voltage Sags Mitigation with An Integrated Gate Commutated Thyristor Based Dynamic Voltage Restorer" In 8th International Conference on Harmonics and Quality of Power Proceedings,(Vol.1,pp.561-565.IEEE.

[24] Dr. Snv Ganesh, V. Praveen," Fuzzy controlled Dynamic Voltage Regulator for Power Quality Improvement", International Journal of Electrical Power and Power Electronics, Vol-1, Issue-1, pp-23-32, 2018.

[25] 1S.Deepa , 2Lavanya Dhanesh ,3P.Elangovan," Optimal Fuzzy Controller ForPower Quality Improvement Of Dynamic

Voltage Restorer Using Bacterial Foraging Algorithm", International Journal of Advanced Science and Technology, pp. 1015, Vol. 28, No. 19, 2019.

[26] Dung Vo Tien, Radomir Gono ID and Zbigniew Leonowicz, "A Multifunctional Dynamic Voltage Restorer for Power Quality Improvement", Energies 2018, 11, 1351; doi:10.3390/en1106135.27372749.

[27] Neelam Kassarwani, Jyoti Ohri \& Alka Singh," Design and performance of dynamic voltage restorer using genetic algorithm", International Journal of Electronics, 105:1, 88-103, DOI: 10.1080/00207217.2017.134782. 
[28] Franklyn B. Moreno, Juan E. Palacios, Johnny Posada, Jesus A. Lopez," Implementation and evaluation of a new DVR topology with AC link for series compensatio", Electric Power Systems Research 181 (2020) 106184.

[29] Nageswara Rao Sikha, Bavanam NavaJeevan Reddy, "Fuzzy Based Dynamic Voltage Restorer for Sag Mitigation to Improve Electric PowerQuality" International Journal of Engineering Research \& Technology(IJERT), ISSN: 2278-0181,Vol. 7 Issue 05, May-2018.

[30] K.Sandhya,Dr A. Jaya Laxmi,Dr. M.P Soni, "Design of PI and Fuzzy controller for Dynamic Voltage Restorer",2012 AASRI Conference on Power and Energy Systems, 149-155,2012

[31] Gopinath,C. Yaashuwanth, R. Ramesh, J. R. Maglin, and T. Ajith Bosco Raj, "Analysis and Mathematical Model for Restitution of Voltage Using Dynamic Voltage Restorer", Hindawi Publishing Corporation, Volume 2014, Article ID 845873, 18 pages

[32] V. K. Remya, P. Parthiban, V. Ansal and B. Chitti Babu, "Dynamic Voltage Restorer (DVR) - A Review",Journal of Green Engineering",Vol: 8 Issue4, page 519-572, 2018

[33] S. Sherine1, G.Hemavathi , "FUZZY CONTROLLER BASED DYNAMIC VOLTAGE RESTORER FOR VOLTAGE FLUCTUATIONS", International Journal of Pure and Applied Mathematics Volume 119 No. 12 2018, 8241-8253 ISSN: 1314-3395 